\title{
HIV Escape From Peptide Fusion Inhibitors
}

\section{Nidhi Gupta* ${ }^{* \neq 1}$, Emmanuel Desmezieres ${ }^{1}$, Russell Vassell ${ }^{1}$, Yong $\mathrm{He}^{1}$, Paul Wingfield ${ }^{2}$ and Carol D Weiss ${ }^{1}$}

\author{
Address: ${ }^{1}$ FDA/CBER, 8800 Rockville Pike, Bethesda, Maryland 20892 and ${ }^{2}$ NIH/NIAMS, 8800 Rockville Pike, Bethesda, Maryland 20892 \\ Email: Nidhi Gupta* - gupta@ncber.fda.gov \\ * Corresponding author $¥$ Presenting author
}

from 2005 International Meeting of The Institute of Human Virology

Baltimore, USA, 29 August - 2 September 2005

Published: 8 December 2005

Retrovirology 2005, 2(Suppl I):P34 doi:10.1 I86/I742-4690-2-SI-P34

HIV envelope glycoprotein (Env) mediates infection by fusing virus with cellular membranes. Fusion inhibitors, a new class of antiretroviral drugs, inhibit HIV infection by binding to gp41 to form a peptide-gp $416 \mathrm{HB}$ that is fusion-incompetent. To understand resistance mechanisms to peptide fusion inhibitors that will aid development of new drugs, we generated an escape-mutant virus against an N-peptide inhibitor. We found that two mutations in gp41, one each in the N- and C- heptad repeats, confer early resistance to the $\mathrm{N}$ peptide. These same mutations also confer resistance to a $\mathrm{C}$ peptide inhibitor. This is the first report of cross-resistance among peptide fusion inhibitors. Curiously, the $\mathrm{N}$ mutation alone or in combination with $\mathrm{C}$ mutation also conferred increased sensitivity to soluble CD4 and was associated with faster growth kinetics and larger syncytia. These results suggest global changes in Env involving receptor activation and fusion kinetics. Using thermal denaturation studies, involving $\mathrm{N}$ and $\mathrm{C}$ peptides containing wild type ( $\mathrm{Nw}$ or $\mathrm{Cw}$ ) or resistance residues $(\mathrm{Nm}$ or $\mathrm{Cm})$, which self-assemble into a $6 \mathrm{HB}$, we showed that the $\mathrm{N}$ mutation improved the energetics of the viral $6 \mathrm{HB}$, however, the energetics of the $6 \mathrm{HB}$ formed with the inhibitor and the $\mathrm{N}$ and $\mathrm{C}$ peptides is not afffected. Thus, our results demonstrate a resistance pathway that appears to involve both kinetic and thermodynamic factors that regulate virus entry and work indirectly to reduce the ability of fusion inhibitors to bind Env. 